\title{
Communication \\ Generation of a Strength Gradient in Al-Cu-Ca Alloy Foam via Graded Aging Treatment
}

\author{
Wei Zhao ${ }^{1}$, Siyuan $\mathrm{He}^{1, *}$, Chen Zhang ${ }^{1}$, Yuxuan $\mathrm{Li}^{2}$, Yi Zhang ${ }^{2}$ and Ge Dai ${ }^{2}$ \\ 1 State Key Laboratory of Bioelectronics, School of Biological Science \& Medical Engineering, \\ Southeast University, Nanjing 210096, China; 230189176@seu.edu.cn (W.Z.); zhangchen97@seu.edu.cn (C.Z.) \\ 2 Jiangsu Key Laboratory of Advanced Metallic Materials, School of Materials Science \& Engineering, \\ Southeast University, Nanjing 211189, China; 220202182@seu.edu.cn (Y.L.); 230139169@seu.edu.cn (Y.Z.); \\ daige@seu.edu.cn (G.D.) \\ * Correspondence: siyuan_he@seu.edu.cn
}

Citation: Zhao, W.; He, S.; Zhang, C.; Li, Y.; Zhang, Y.; Dai, G. Generation of a Strength Gradient in Al-Cu-Ca Alloy Foam via Graded Aging Treatment. Metals 2022, 12, 423. https://doi.org/10.3390/met12030423

Academic Editor: Andrey Belyakov

Received: 2 November 2021

Accepted: 22 December 2021

Published: 28 February 2022

Publisher's Note: MDPI stays neutral with regard to jurisdictional claims in published maps and institutional affiliations.

Copyright: (c) 2022 by the authors. Licensee MDPI, Basel, Switzerland. This article is an open access article distributed under the terms and conditions of the Creative Commons Attribution (CC BY) license (https:// creativecommons.org/licenses/by/ $4.0 /)$.

\begin{abstract}
In this study, a strength gradient is produced in Al-Cu-Ca alloy foam by aging treatment with a temperature gradient. The microscopic results show that the morphology and the amount of $\mathrm{Al}_{2} \mathrm{Cu}$ strengthening precipitates in the base alloy change with the local aging temperature. Graded microstructures in the base alloy are realized along with the temperature gradient, subsequently producing the strength gradient in the Al-Cu-Ca foam. Under compression, the lower strength portion of the foam sample firstly collapsed until complete densification and then extended to the higher strength portion, suggesting a notable strength gradient. The tailorable graded aging treatment provided a higher degree of freedom in designing and producing the strength gradient in aluminum foam.
\end{abstract}

Keywords: porous materials; gradient strength; $\mathrm{Al}-\mathrm{Cu}-\mathrm{Ca}$ alloy foam; aging treatment; mechanical properties; microstructure

\section{Introduction}

A tailorable strength gradient endows aluminum foam with extraordinary potentials to improve crashworthiness, namely lower transmitted stress and higher energy absorption [1]. To date, the strength gradient in aluminum foam was achieved by generating a density gradient in parallel to the foaming direction [2,3]. However, this method restrained the degree of freedom in the strength gradient to the foaming direction. Alternatively, generating a graded microstructure in base materials is another feasible way to achieve a mechanical properties gradient similar to the method of surface nanocrystallization [4]. By engendering incoherent precipitates in the base alloy, the aging treatment enhanced the strength of Al-Cu alloy foam in the function of the aging temperature [5]. Due to the low thermal conductivity of aluminum foam, a large gradient of temperature is achievable through inhomogeneous heating during aging treatment. Then, inhomogeneous microstructure in the base alloy may be realized in accordance with the graded aging temperature field so as to produce a strength gradient in aluminum foam.

In this study, the graded aging method was adopted to realize a strength gradient in Al-Cu-Ca aluminum foam. The content of $\mathrm{Ca}$ and $\mathrm{Cu}$ was sophisticatedly balanced to realize the aluminum alloy foam with both a homogenous pore structure and good aging-strengthening effects. The microstructures and strength gradient in Al-Cu-Ca alloy foam were examined.

\section{Experimental Procedure}

The Al-Cu alloy with a high $\mathrm{Cu}$ content of $9 \mathrm{wt} \%$ was selected to ensure sufficient copper solute was maintained in the base alloy, in addition to the $\mathrm{Cu}$ consumed by generating the Al-Cu-Ca intermetallic compounds. A total of $1.0 \mathrm{wt} \% \mathrm{Ca}$, combined with $5.0 \mathrm{wt} \%$ 
$\mathrm{SiC}$ (1000 mesh) powers, were adopted as melt foam stability agents and introduced into the alloy melt with 30 min stirring. According to the empirical knowledge of preliminary experiments, Ca plays a significant role in facilitating the dispersion of $\mathrm{SiC}$ powders in the aluminum melt. The $1.5 \mathrm{wt} \% \mathrm{TiH}_{2}$ powder $\left(300^{\circ} \mathrm{C}\right.$ preheated), acting as a foaming agent, was dispersed into the aluminum alloy melt with high-speed stirring. After the melt was completely foamed, the foam was cooled down by spraying water until solidification. The Al-Cu foam, with a porosity of $81.2 \%$, was successfully prepared, and the pore structure was shown in Figure 1a. The column samples were cut in the diameter of $30 \mathrm{~mm}$ with a length of $150 \mathrm{~mm}$, were heated in a resistance furnace at $540{ }^{\circ} \mathrm{C}$ for $6 \mathrm{~h}$ and subsequently quenched to room temperature. After that, the samples were wrapped using thermal insulation material, and the two ends of samples were exposed to the different thermal conditions for $7 \mathrm{~h}$. The aging process was carried out by heating one end at $180^{\circ} \mathrm{C}$ and cooling the other end by spraying water. Then, the sample was air-cooled. Five thermocouples were used to monitor the temperature evolution at the five equidistant positions along with the axial orientation of the samples, as illustrated in Figure $1 \mathrm{~b}$.
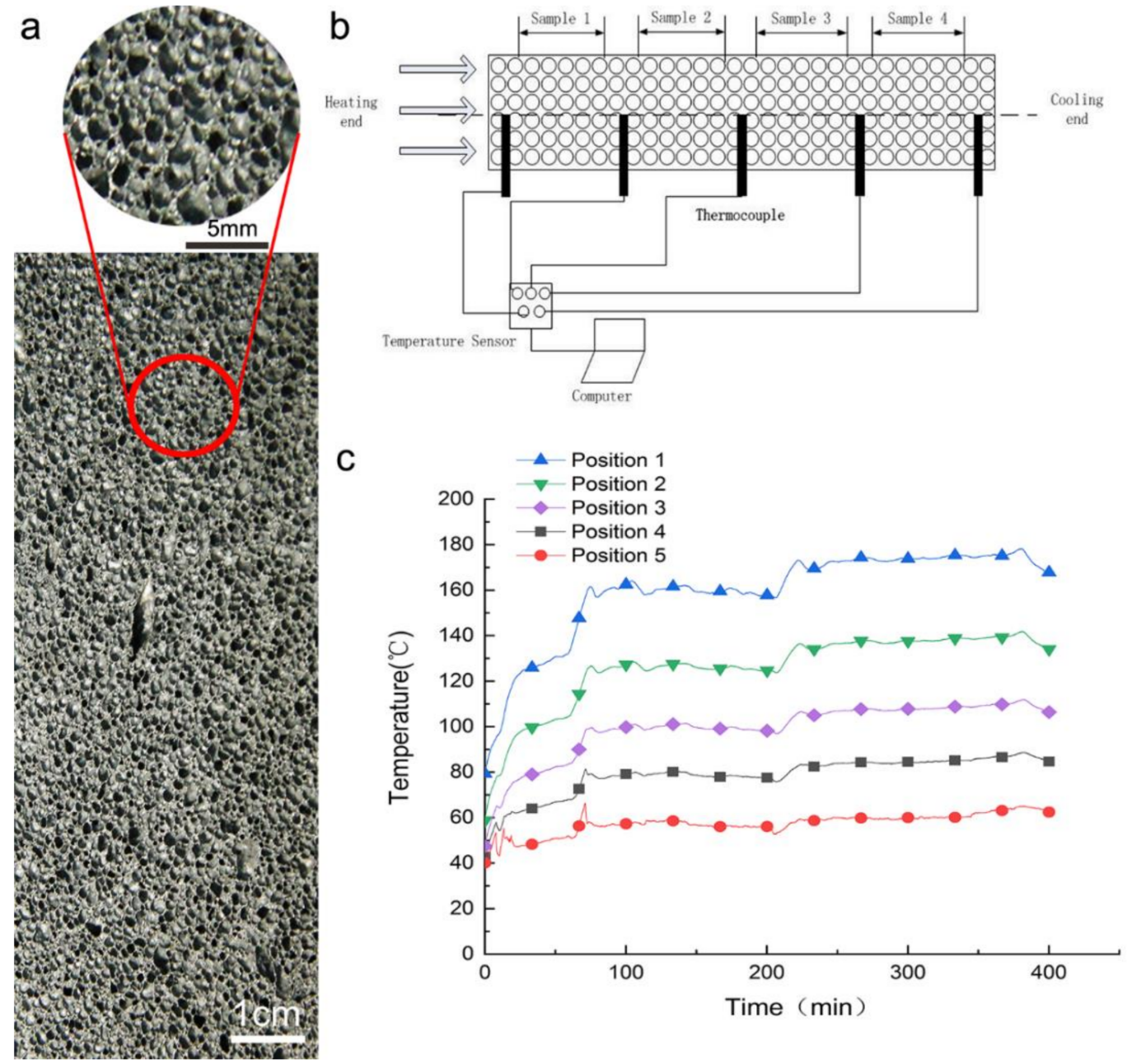

Figure 1. (a) Section image of the Al-Cu-Ca alloy foams (b) Schematic diagram of temperature detection during aging (c) Temperature distribution in samples during aging.

Four specimens with an identical length of $20 \mathrm{~mm}$ were sectioned from the samples along the temperature gradient, marked as samples 1, 2, 3, 4, respectively. Every specimen was polished and etched with a $30 \% \mathrm{NaOH}$ solution. The corresponding microstructure was analyzed by scanning electron microscopy (SEM) with an energy dispersive X-ray spectrometer (EDS). X-ray diffraction (XRD) was used to reveal the composition of precipi- 
tations. In addition, another sample with a length of $40 \mathrm{~mm}$ was sectioned from the graded aged sample to examine the compressive behaviors. All the samples were compressed with a universal testing machine with a loading speed of $3 \mathrm{~mm} / \mathrm{min}$.

\section{Results and Discussion}

The longitudinal section of the Al-Cu-Ca alloy foam sample is given in Figure $1 \mathrm{a}$. The homogeneously distributed pores with an average size of $2 \mathrm{~mm}$ and a strut thickness of $150 \mu \mathrm{m}$ were observed on the cross-section of the sample. The introduction of SiC powers is believed to provide an additional contribution to stabilize the alloy melt foam on account of the low content of $\mathrm{Ca}$. The analogous contribution of tiny-sized particles on foam stabilization is not only observed in aluminum melt foam [6] but also in aqueous foam [7].

The temperature evolutions of the five positions in the sample were recorded by thermocouples and are presented in Figure 1c. There is an evident discrepancy of temperature at different positions of the sample as a result of the low thermal conductivity of the Al-Cu-Ca alloy foam. From the heating end to the cooling end, the temperatures were maintained at $175{ }^{\circ} \mathrm{C}, 139{ }^{\circ} \mathrm{C}, 109{ }^{\circ} \mathrm{C}, 85^{\circ} \mathrm{C}$, and $60^{\circ} \mathrm{C}$ with respect to position $1,2,3,4$, and 5 . The temperature gradient of $0.82{ }^{\circ} \mathrm{C} / \mathrm{mm}$ was calculated in relation to the distance between the temperature measurement positions in the foam sample.

The temperature gradient in the foam sample would lead to the graded microstructure of base alloy in accordance with the temperature field. Figure $2 \mathrm{a}$ gives the microstructures of the sample without aging treatment; Figure $2 b, c$ show the samples aged the cooling end and heating end, respectively. Based on EDS and XRD analysis, Al-Cu, Al-Cu-Ca, and Al-Ca-Ti eutectic phases were detected in all the samples, as shown in Figure $2 \mathrm{~d}$. Table 1 gives the chemical compositions of $\mathrm{Al}-\mathrm{Cu}-\mathrm{Ca}$ alloys. The Al-Cu-Ca eutectic phases, in the form of bright layers and feathers, and some gray particles of $\mathrm{Al}_{20} \mathrm{CaTi}_{2}$ eutectic phases and $\mathrm{SiC}$ can be observed in all the metallographies. In the untreated sample, the $\mathrm{Al}_{2} \mathrm{Cu}$ eutectic phase was present in the form of a bright network (as shown in Figure 2a). Once undergoing the aging treatment at the cooling end, a small amount of short-rod-shaped $\mathrm{Al}_{2} \mathrm{Cu}$ precipitates appeared in the base metal, potentially attributed to the low nucleation rate of the precipitation at a lower aging temperature of $60{ }^{\circ} \mathrm{C}$. At the heating end of the foam, the base alloy underwent the aging treatment at approximately $175^{\circ} \mathrm{C}$ and generated plentiful short-rod-shaped $\mathrm{Al}_{2} \mathrm{Cu}$ precipitates, which act as one of the primary strengthening phases in Al-Cu-Ca alloys. The close relationship between the precipitation of the $\mathrm{Al}_{2} \mathrm{Cu}$ strengthening phases and the aging temperature was also observed in Reference [8]. The graded temperature field in the foam leads to the precipitation of the strengthened phases varied with position, subsequently producing the Al-Cu-Ca alloy foam with a strength gradient. The residual stress derived from the temperature gradient in aluminum foam may also play a considerable role in deformation behaviors [9], which will be studied in the future.

Table 1. Chemical compositions of Al-Cu-Ca alloys in Figure 2.

\begin{tabular}{ccccccc}
\hline $\begin{array}{c}\text { Element } \\
\text { (wt.\%) }\end{array}$ & a1 & a2 & b1 & b2 & c1 & c2 \\
\hline $\mathrm{Al}$ & 49.7 & 60.0 & 42.8 & 70.2 & 44.9 & 56.0 \\
$\mathrm{Cu}$ & 41.8 & 37.3 & 48.4 & 24.7 & 45.9 & 39.1 \\
$\mathrm{Ca}$ & 8.5 & 2.7 & 8.8 & 5.1 & 9.2 & 4.9 \\
\hline
\end{tabular}




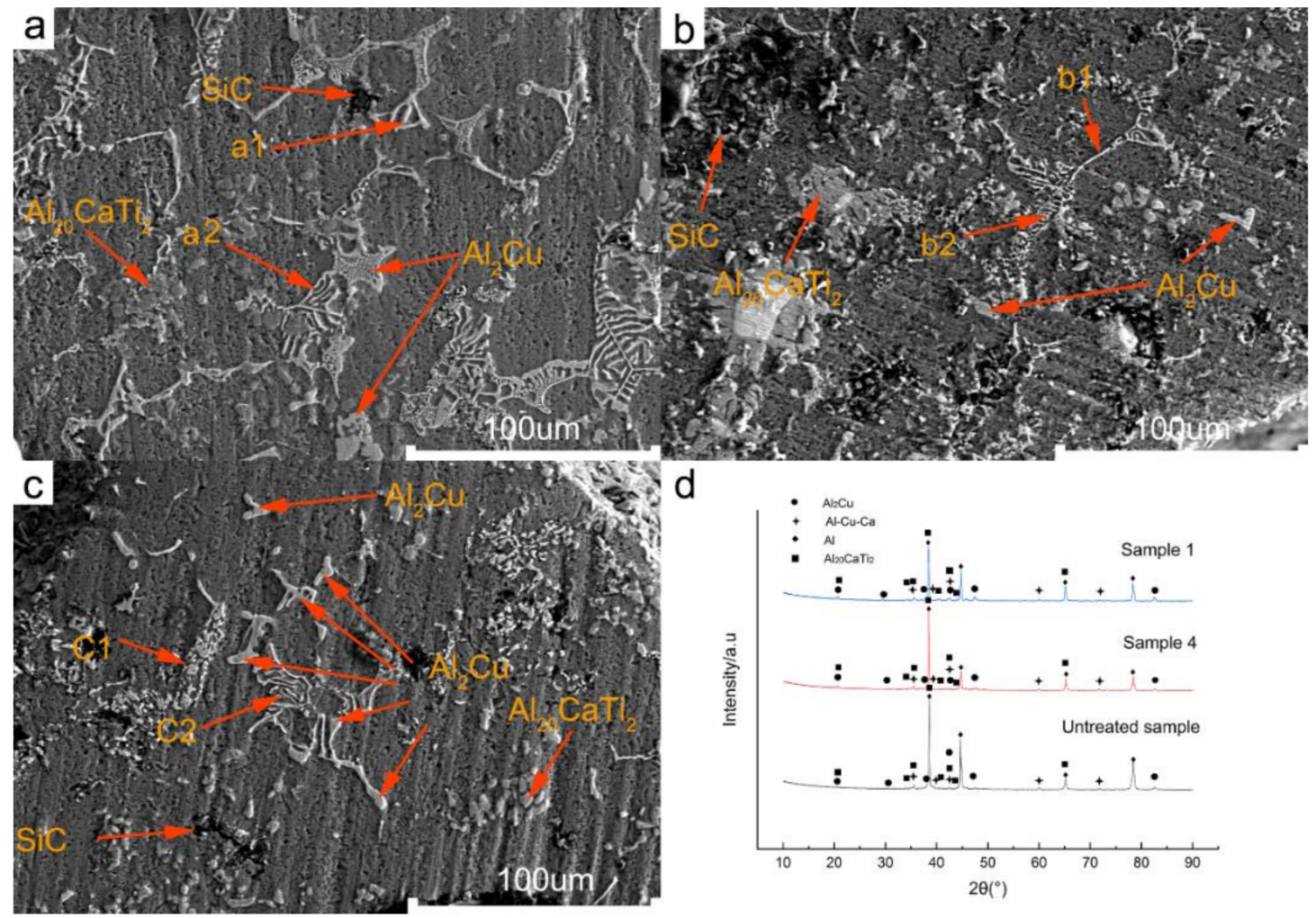

Figure 2. SEM (scanning electron microscopy) of cross-section at different temperature intervals (a) untreated sample, (b) sample 4 aged with low temperature, (c) sample 1 aged with hightemperature aging sample 1. (d) XRD of aging samples and untreated sample.

Figure 3a gives the compressive stress-strain curves of the foam samples 1, 2, 3, and 4, corresponding to the aging temperatures dropping from $175^{\circ} \mathrm{C}$ to $60^{\circ} \mathrm{C}$, respectively. The results show that the yielding stress of samples $1,2,3$, and 4 decreases with the increase of the distance between the position of the samples to the heating surface. Due to the proper aging temperature at the heating end, the strength of sample 1 was largely improved as a result of abundant $\mathrm{Al}_{2} \mathrm{Cu}$ precipitates in the base alloy. In comparison, a lower aging temperature results in the poor precipitation of the strengthening phase, generating a low regional yielding stress of the sample near the cooling end. It should be noted that the yield stress of the sample at the heating end, i.e., sample 1, is $40.7 \%$ higher than that at the cooling end, i.e., sample 4 , showing a significant strength difference after graded aging treatment. In Figure $3 b$, the curve of the graded-aging treated sample has a higher yielding stress and plateau stress than the untreated one. It seems that the plateau region of the graded-aging treated sample could be divided into two parts at the strain of 0.4 , indicating two stages of the deformation. Before this strain, the stress curve of the aged sample oscillates around stress of $17 \mathrm{MPa}$, which is consistent with the plateau stress of sample 2. After the strain of 0.4 , the stress is enhanced to the level of $20 \mathrm{MPa}$, that is, the plateau stress of sample 1. The energy absorption capacity of aluminum foams is defined as the energy required to deform the sample to a specific strain and can be evaluated by integrating the area under the stress-strain curve as Equation (1) [10].

$$
W=\int_{0}^{\varepsilon_{m}} \sigma d \varepsilon
$$

where the $\sigma$ is the stress, and the $\varepsilon$ is the stain, $\varepsilon_{m}$ is the maximum strain. Figure $3 c$ compare the energy absorption curves of untreated samples and gradient samples. It seems that the 
sample with strength gradient base alloy possesses better energy absorption capacity than the untreated counterpart.

a

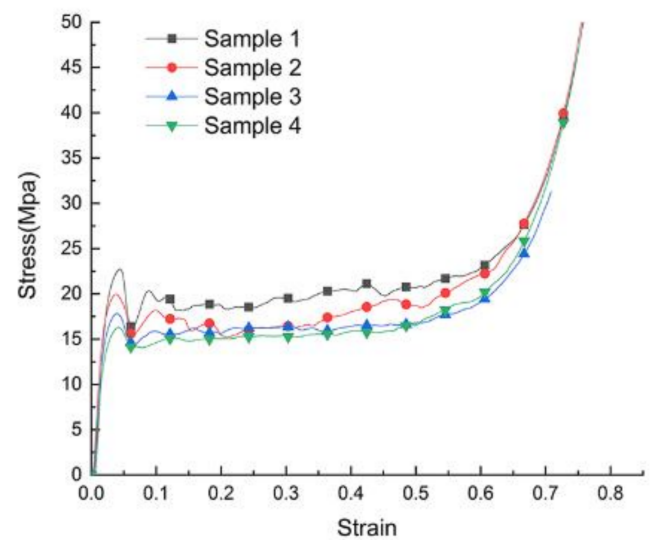

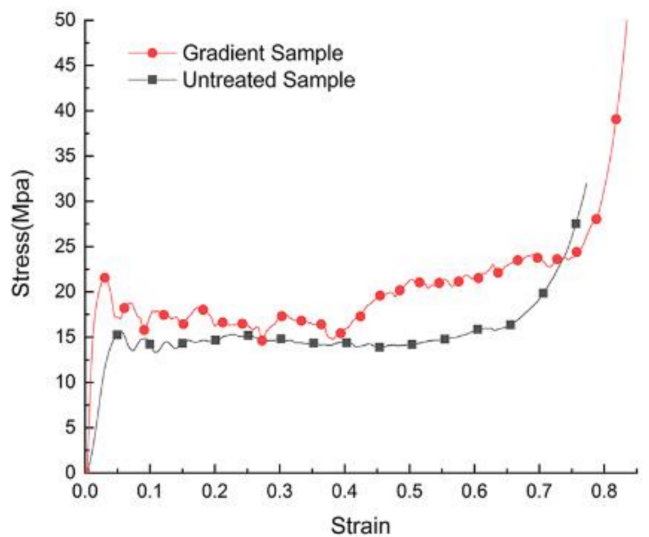

C

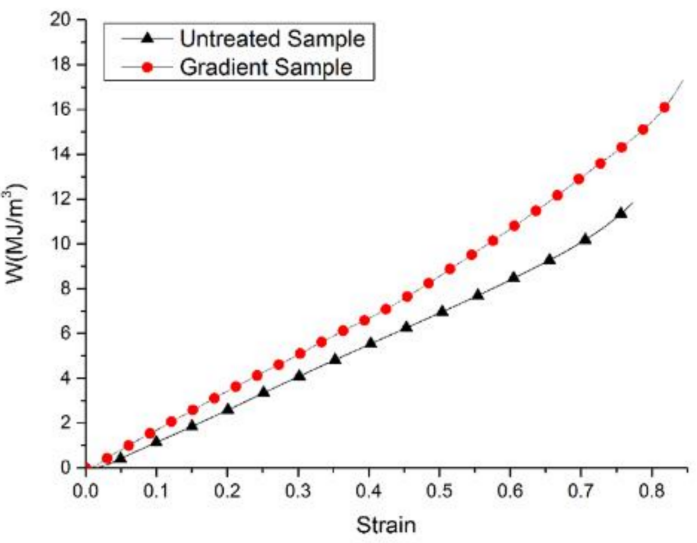

Figure 3. (a) Stress-strain curves at different locations (b) Stress-strain curves of gradient samples and untreated samples (c) Energy absorption curves of gradient samples and untreated samples.

The stage deformation mode was also observed in the quasi-static compression experiment of the aging-treated sample, as shown in Figure 4. The sample was placed in the orientation that the regional strength gradually increases from top to bottom, namely the bottom of the sample is closer to the heating end of aging treatment. During the compression, the collapse of cellular structure initiated and accumulated in the upper portion of the sample until the deformation of $50 \%$, then the bottom portion triggered the deformation after the upper portion nearly complete densification. The deformation behavior could be attributed to the difference in strength between the upper and lower portion of the specimen, originating from the different temperatures of aging treatment. Considering that the aging temperature field in Al-Cu-Ca alloy foam is more tailorable, the method proposed in this study may lead to diverse strength gradients in aluminum alloy foam in addition to the foaming direction. 


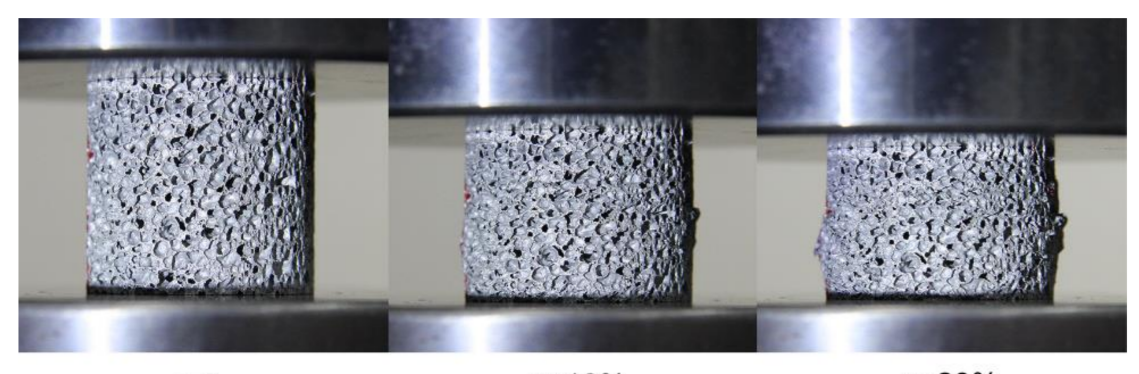

$\varepsilon=0$

$\varepsilon=10 \%$

$\varepsilon=20 \%$

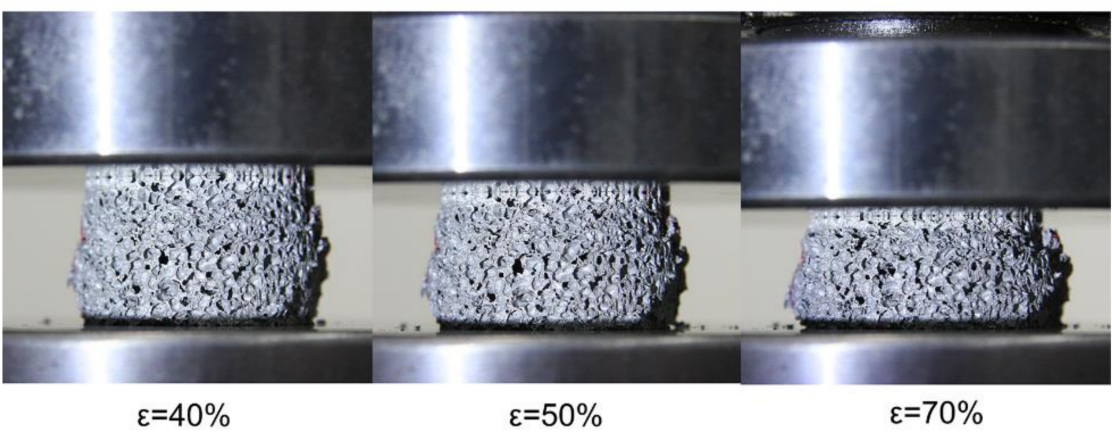

Figure 4. Deformation mode during compression of gradient sample.

\section{Conclusions}

The aging treatment with a gradient temperature field gives rise to a graded distribution of $\mathrm{Al}_{2} \mathrm{Cu}$ precipitates in the base alloy of $\mathrm{Al}-\mathrm{Cu}-\mathrm{Ca}$ alloy foam. In turn, the strength gradient of the $\mathrm{Al}-\mathrm{Cu}-\mathrm{Ca}$ alloy foam is realized and is tailorable by choosing the temperature field of aging. Under compression, the stage collapse of the strength-graded $\mathrm{Al}-\mathrm{Cu}-\mathrm{Ca}$ alloy foam is observed, in which the collapse initiates at the low strength portion and extends to the higher strength portion after the nearly complete densification of the low strength portion.

Author Contributions: Conceptualization, W.Z. and S.H.; methodology, W.Z. and S.H.; software, C.Z.; validation, S.H.; formal analysis, Y.L.; investigation, W.Z. and Y.Z.; resources, S.H.; data curation, C.Z. and Y.Z.; writing—original draft preparation, W.Z.; writing—review and editing, S.H. and G.D.; visualization, Y.L.; supervision C.Z.; project administration, none.; funding acquisition, none. All authors have read and agreed to the published version of the manuscript.

Funding: This research was funded by the National Natural Science Foundation of China [grant NO. 52071075 and grant NO.11572087].

Institutional Review Board Statement: Not applicable.

Informed Consent Statement: Not applicable.

Data Availability Statement: Not applicable.

Conflicts of Interest: The authors declare no conflict of interest.

\section{References}

1. Yu, X.; Qin, Q.; Zhang, J.; He, S.; Xiang, M.; Wang, C.; Wang, T.J. Crushing and energy absorption of density-graded foam-filled square columns: Experimental and theoretical investigations. Compos. Struct. 2018, 201, 423-433. [CrossRef]

2. He, S.Y.; Zhang, Y.; Dai, G.; Jiang, J.G. Preparation of density-graded aluminum foam. Mater. Sci. Eng. A. 2014, 618, 496-499. [CrossRef]

3. Yi, Z.; Xiao-yun, Z.; Ke, W.; Si-yuan, H.; Jia-gui, L.; Wei, Z.; Xiao-lu, G.; Jin, Y. Fabrication of functionally radial graded metallic foam. Mater. Lett. 2020, 264, 127292. [CrossRef]

4. Maleki, E.; Unal, O.; K. Reza Kashyzadeh; Surface layer nanocrystallization of carbon steels subjected to severe shot peening: Analysis and optimization. Mater. Charact. 2019, 175, 109877. [CrossRef] 
5. Huang, L.; Wang, H.; Yang, D.H.; Ye, F.; Wang, S.Q.; Lu, Z.P. Effects of calcium on mechanical properties of cellular Al-Cu foams. Mater. Sci. Eng. A. 2014, 618, 471-478. [CrossRef]

6. Körner, C. Foam formation mechanisms in particle suspensions applied to metal foams. Mater. Sci. Eng. A. 2008, 495, 227-235. [CrossRef]

7. Hunter, T.N.; Pugh, R.J.; Franks, G.V.; Jameson, G.J. The role of particles in stabilising foams and emulsions. Adv. Colloid Interface Sci. 2008, 137, 57-81. [CrossRef] [PubMed]

8. Zou, Y.; Cao, L.; Wu, X.; Wang, Y.; Sun, X.; Song, H.; Couper, M.J. Effect of ageing temperature on microstructure, mechanical property and corrosion behavior of aluminum alloy 7085. J. Alloys Compd. 2020, 823, 153792. [CrossRef]

9. Zhou, W.; Zhou, H.; Zhang, R.; Pei, Y.; Fan, D. Measuring residual stress and its influence on properties of porous $\mathrm{ZrO} 2 /(\mathrm{ZrO} 2+\mathrm{Ni})$ ceramics. Mater. Sci. Eng. A. 2015, 622, 82-90. [CrossRef]

10. Wang, Z.; Li, Z.; Ning, J.; Zhao, L. Effect of heat treatments on the crushing behaviour and energy absorbing performance of aluminium alloy foams. Mater. Des. 2009, 30, 977-982. [CrossRef] 